\title{
UMA CARTA INÉDITA DE BAUDELAIRE A Auguste Lacaussade
}

\author{
Andrea Schellino
}

Uma carta de Baudelaire a Auguste Lacaussade foi posta à venda em 2016 pelo livreiro Julien Paganetti, do Autographes des Siècles, em Lyon. O fac-símile dela, página in-8o, foi reproduzido no site da livraria. Eis o texto da carta:

Caro Senhor,

irei talvez vê-lo na ópera esta noite, apesar de saber a obra de cor. Amanhã de manhã, você terá cópias, e o final, amanhã à noite 19. Aproveite as suas duas entradas. Pois presumo que as recebeu.

Não irei além de 24 páginas. Eu sei contar. Estou seguro de estar fazendo algo bom. Aliás, estou sofrendo a irritação produzida pelas infelicidades da $\mathbf{1}^{\mathrm{a}}$ representação.

Todo seu

C. B.

Rogo-lhe, não esqueça de pedir a Leconte de Lisle de pensar em mim. Isso não deve importuná-lo e, para ele, é fácil fazê-lo. 

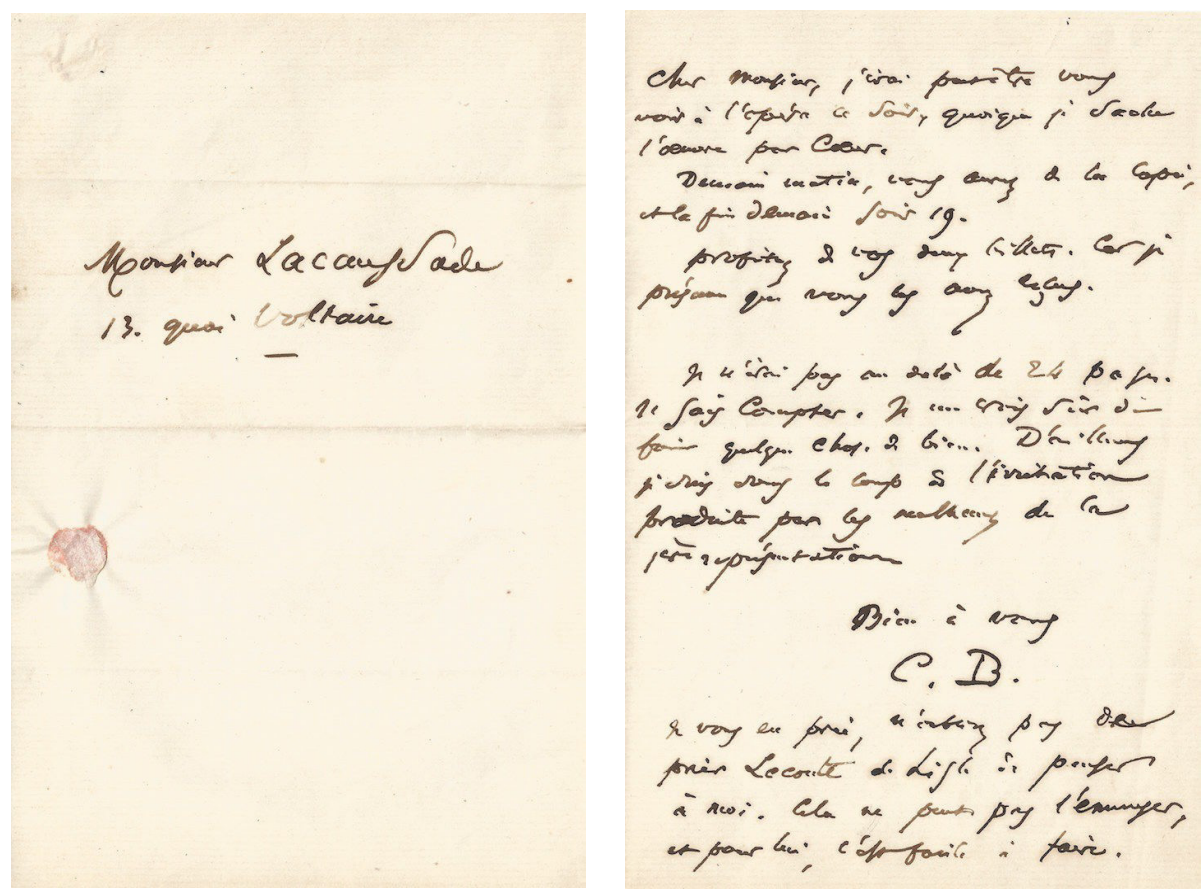

A menção "amanhã à noite 19" permite datar a carta na segunda-feira, 18 de março de 1861. Em duas cartas que precedem esta, Baudelaire (1973, CPl II, pp. 132-133) já prometia seu artigo a Lacaussade para 18 de março.

A obra que Baudelaire sabe "de cor" é Tannhäuser. Assistiu à estreia na Ópera de Paris na quarta-feira 13 de março. Uma segunda representação, anunciada para o dia 15, foi adiada para o dia 18, por motivo de indisposição do tenor, Albert Niemann, que cantava o papel-título; uma terceira representação, que foi a última, ocorreu no domingo, 24 de março.

A carta, não timbrada, foi provavelmente entregue por Baudelaire na casa de Lacaussade, quai Voltaire n⿳0 13, como as três outras cartas datadas do mesmo mês de março de 1861 (CPl II, pp. 132-133 e Lettres à Baudelaire, 1973, p. 43). Lacaussade constava na lista de envio de exemplares da primeira edição das Flores do mal (13 de junho de 1857; CPl I, p. 407) e da segunda edição (17 de janeiro de 1861; CPl II, p. 125). Outras cinco cartas de Baudelaire a Lacaussade são conhecidas e constam na edição da Pléiade. São todas do ano de 1861 (início de maio, 7 de maio, meados de agosto, 21 de agosto e 7 de setembro; CPl II, pp. 147-148, 158, 186, 190-191) e dizem respeito à efêmera colaboração de Baudelaire com a Revue Européenne. É 
nessa revista que seu artigo sobre "Richard Wagner" foi publicado, em 1o de abril de 1861. Baudelaire, naquele dia, descreve à sua mãe a composição febril daqueleartigo, "improvisadoem três dias" e finalizado sob "a obsessão da imprensa” ( $C P l$ II, p. 140). Na sequência, enviará quatro sonetos à Revue Européenne, que os publicará dia 15 de setembro ("A prece de um pagão", "O rebelde", "O admoestador" e "Epígrafe para um livro condenado") e e dia $1^{\circ}$ de novembro ("Recolhimento"). ${ }^{3}$ Ele havia pensado confiar à mesma revista "O pintor da vida moderna" (que será publicado no Figaro nos dias 26, 29 de novembro e 3 de dezembro de 1863), os "Peintres philosophes" (Pintores filósofos), textoanunciadovárias vezes com diversos títulos, entre 1857 e 1866, mas que permaneceu no estado de esboço, ${ }^{4}$ e "Chateaubriand, père des Dandies, et sa postérité” (Chateaubriand, pai dos Dândis, e sua posteridade), projeto que permaneceu inacabado.

Lacaussade era ligado a Leconte de Lisle. Daí o post-scriptum da carta, pedindo-lhe para intervir junto a este a fim de que escrevesse uma resenha sobre a segunda edição das Flores do mal, publicadas por PouletMalassis e de Broise no início de fevereiro de 1861. Em maio, Baudelaire solicita novamente a Lacaussade, duas vezes, para que intervenha nesse sentido ( $C P l$, pp. 148 e 158). A resenha de Leconte de Lisle será publicada na última entrega da Revue Européenne, em 1o de dezembro de 1861.

Auguste Lacaussade (1815-1897), que havia sido o secretário de Sainte-Beuve entre 1844 e no início dos anos cinquenta, ${ }^{6}$ era também poeta (Poèmes et paysages, Ducloux, 1852). Após ter colaborado na Revue Contemporaine, sob a direção de Alphonse de Calonne, fundou

$1 \mathrm{O}$ artigo foi em seguida reproduzido por Adolphe Giacomelli, empresário parisiense de Wagner, no La Presse Théâtrale et Musicale, dias 14 e 21 de abril, e 5 de maio de 1861; essa publicação foi interrompida por causa da retomada de um trecho do artigo em uma plaqueta na editora Dentu, em maio de 1861, com o título Richard Wagner e "Tannhäuser" em Paris.

2 Na rubrica "Poésies" (Revue Européenne, pp. 341-343), em que constam igualmente poemas de Leconte de Lisle e Léandre Brocherie. Uma resenha severa dos Paraísos artificiais, no "Bulletin bibliographique" na Revue Européenne, havia sido publicada em julho de 186o. O autor, Ernest Chesneau, denunciava a "singular doença moral" de Baudelaire, sua "mania pelo estranho".

3 Na rubrica "Poésies" (Revue Européenne, p. 159).

4 Claude Pichois elaborou uma lista dos títulos considerados por Baudelaire. Desse projeto inacabado, que era dirigido contra a escola lyonnaise de pintura, culpada de subordinar o belo ao bem, resta-nos apenas um esboço e notas (OC II, 598-607, pp. 1.377-1.382).

5 É com este título que Baudelaire, no início de maio de 1861 , anuncia a Lacaussade seu ensaio sobre o dandismo literário (CPl II, p. 147).

6 Ver Sainte-Beuve (1947, pp. 526-527) e (1958, pp. 29-30).

Remate de Males, Campinas-SP, v. 37, n. 1, pp. 485-489, jan./jun. 2017 
em fevereiro de 1859 a Revue Européenne, impressa por Dentu graças às subvenções do governo imperial. ${ }^{7}$ Essa revista objetivava concorrer com a de Calonne, que havia perdido os favores (e os subsídios) dos ministérios do Interior e da Instrução Pública. Lacaussade convidou Baudelaire a passar da Revue Contemporaine à Revue Européenne, o que agravou ainda mais o desacordo entre Calonne e o poeta. Calonne, que havia adiantado dinheiro a Baudelaire sobre os direitos esperados de algumas obras, exigiu que o reembolsasse. O próprio editor se encontrava em uma situação difícil e ameaçado de penhora: ${ }^{8}$ a investigação foi finalizada em 26 de novembro de 1858 . Mas ele resistiu às provações, e a Revue Contemporaine retomou suas atividades, até absorver a Revue Européenne de Lacaussade, em dezembro de 1861.

Tradução de Gilles Jean Abes

Revisão de Eduardo Veras

\section{REFERÊNCIAS BIBLIOGRÁFICAS}

BAUDELAIRE, Charles. Lettres à Lacaussade, de 18 de março de 1861. (Inédito)

BAUDELAIRE, Charles. Correspondance. 2v. Texte établi, présenté et annoté par Claude Pichois avec la collaboration de Jean Ziegler. Paris: Gallimard, 1973. (Coll. Bibliothèque de la Pléiade)

BAUDELAIRE, Charles. Oeuvres complètes. 2v. Texte établi, présenté et annoté par Claude Pichois. Paris: Gallimard, 1975-1976. (Coll. Bibliothèque de la Pléiade)

CREPET, Jacques \& FATOU, Étienne. Baudelaire, fin manoeuvrier. La Nef, no 43, juin. 1948, pp. 3-21. Disponível em: <http://www.revues-litteraires.com/articles. php?lng=fr\&pg=1373>. Acesso em: 8 jul. 2017.

LISLE, Charles Leconte de. Les Fleurs du mal, par M. Ch. Baudelaire. In: GUYAUX, André. Baudelaire. Un demi-siècle de lectures des Fleurs du mal (1855-1905). Paris: Presses de l'Université Paris-Sorbonne, 2007, pp. 341-143. (Coll. Mémoire de la Critique)

MAINGARD, Louis F. Revue Européenne: étude bibliographique. Revue d'Histoire Littéraire de la France, XXIXe année, no 3, juil.-sept. 1922, pp. 354-362.

7 Ver Louis F. Maingard (1922, pp. 354-362).

8 Sobre o "caso Calonne" (Baudelaire a Lacaussade, início de maio de 1861, CPl II, p. 148), ver o artigo de Jacques Crépet e Étienne Fatou (1948). Ver também Lettres à Baudelaire (PICHOIS, 1973, pp. 68-72).

Remate de Males, Campinas-SP, v. 37, n. 1, pp. 485-489, jan./jun. 2017 
Uma Carta inédita de Baudelaire a Auguste Lacaussade - 491

PICHOIS, Claude. Lettres à Baudelaire. Avec la collaboration de Vincenette Pichois. Neuchâtel: A la Baconnière, 1973. (Coll. Langages - Études Baudelairiennes IV-V)

SAINTE-BEUVE. Correspondance générale. Selecionada, organizada e anotada por Jean Bonnerot. Tomo V, 2 $2^{\mathrm{a}}$ parte. Paris: Stock, 1947. Disponível em: <https://pmcdn. priceminister.com/photo/Sainte-Beuve-Correspondance-Generale-1041424013_L. jpg>. Acesso em: 5 jul. 2017.

SAINTE-BEUVE. Correspondance générale. Selecionada, organizada e anotada por Jean Bonnerot. Tomo VIII. Toulouse-Paris: Privat-Didier, 1958. 